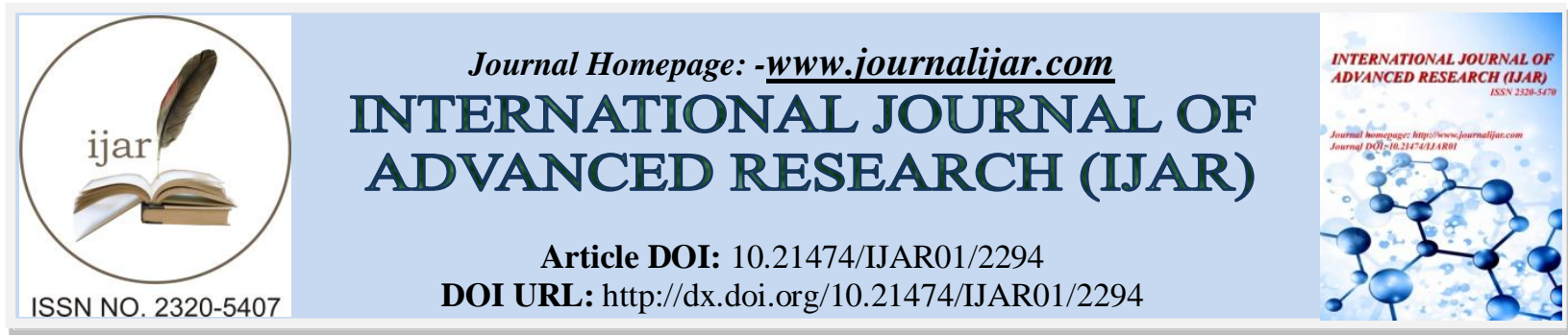

RESEARCH ARTICLE

\title{
A COMPARATIVE ANALYSIS OF RETENTION OF MANDIBULAR DENTURE BASES IN PATIENTS WITH RESORBED RIDGES WITH OR WITHOUT SUBLINGUAL EXTENSION - AN IN VIVO STUDY.
}

\section{Dr. Renu Gupta ${ }^{1}$, Dr. R.P. Luthra ${ }^{2}$ and Dr. Shikha Gupta ${ }^{3}$.}

1. Professor \& Head of department, H.P. Government Dental College, Shimla.

2. Professor \& Principal, H.P. Government Dental College, Shimla.

3. Postgraduate student, H.P. Government Dental College, Shimla.

\section{Manuscript Info}

\section{Manuscript History}

Received: 29 September 2016

Final Accepted: 30 October 2016

Published: November 2016

Key words:-

Denture base, Retention, Ridge resorption, Sublingual extension

\section{Abstract}

Objective: The objective of the present study was to evaluate the effect of sublingual extension on the retention on mandibular denture bases, and compare the retention of the denture bases with or without sublingual extension.

Material and Methods: Twenty healthy subjects with edentulous mandibular ridge with moderate to severe resorption and good oral hygiene were selected as a part of this study. Border molding was done with conventional technique and with sublingual extension. Two acrylic resin denture bases were fabricated for each subject. A specially designed retention apparatus consisting compact force gauge was used to measure retention values of these denture bases.

Results: The dislodging forces for the two denture bases (A and B) of each subject were recorded (in grams) and the collected data was subjected to statistical analysis with IBM SPSS 24 windows software. There was significant increase in retention values $(\mathrm{p}<0.05)$ of denture bases after sublingual extension.

Conclusion:Within the limitations of this study it was concluded that retention could be significantly increased after sublingual extension of the denture bases. Further, long term functional analysis is needed to determine if the subjects could tolerate the amount of dimensional changes created by extension in sublingual region.

Copy Right, IJAR, 2016,. All rights reserved.

\section{Introduction:-}

Ridge resorption is considered as an everlasting challenge for both general practitioner and prosthodontist while dealing with philosophies in complete dentures, resulting in lack of stability and retention. Identification and embodiment of certain mechanical, physical and biologic factors are important to ensure optimal success in complete denture treatment. ${ }^{1}$ Retention in complete denture contributes significantly to the prosthesis wearing experience in patients and mandibular complete denture poses significant challenge in achieving this objective. Chief foundation for such a clinical result is optimal border molding of denture's periphery, which leads to a seal created by closely adapting the denture to its surrounding tissues. This prevents air from entering the fluid interface at the peripheral border seal.

Corresponding Author:-Shikha Gupta.

Address:-Postgraduate student, H.P. Government Dental College, Shimla. 
Denture supporting area in mandible is less than maxilla and some additional factors including movable floor of mouth causes difficulty in establishing a lingual border seal. ${ }^{2,3,4,5}$ Main objective of complete prosthetic procedure is maximum chewing efficiency and for its attainment, maximum retention and stability is indispensable without adversely affecting the surrounding soft tissues. ${ }^{6}$ Loss of peripheral seal mostly occurs in anterior part of alveololingual sulcus because of loss of contact of denture flange with sublingual tissue because of tongue movements resulting in compromised retention. ${ }^{7,8}$ Literature suggests that some important factors dealing with a patient with an unfavorable mandibular ridge is appropriate tongue position and proper use of lingual spaces of denture especially the sublingual crescent space results in optimal retention. Tissue bounding this space moves freely, so that anterior lingual flange can be extended horizontally. ${ }^{10,11,12}$ According to Glossary of Prosthodontic Terms, "sublingual crescent" is the crescent shaped area on the anterior floor of mouth formed by the lingual wall of mandible and adjacent sublingual fold. It is the region of anterior lingual sulcus. Denture extension over the resting tissues of the sublingual crescent area completes the border seal and increases the covering surface by the denture resulting in greater retention by allowing the tongue to aid in holding the denture in place. But care should be taken that pressure exerted on floor of mouth is minimum without restricting the movements of tongue. ${ }^{13,14,15}$

Therefore, an in vivo study had been planned to examine the effect of sublingual extension on retention of denture bases in resorbed ridges.

\section{Material and Methods:-}

The present study was conducted on twenty edentulous subjects, both males and females who reported in the Department of Prosthodontics, H.P Government Dental College, Shimla, Himachal Pradesh.

The study was carried out in the following manner:

1. Evaluation of the patient

2. Making edentulous impression

3. Fabrication of special trays

4. Border molding of first tray in conventional manner

5. Border molding of second tray with sublingual extension

6. Fabrication of master cast

7. Duplication of master cast

8. Fabrication of acrylic resin test bases

9. Measurement of retention of denture bases

10. Analysis of data

Evaluation of the patient:-

Twenty healthy edentulous subjects were evaluated for the following inclusion and exclusion criteria:

\section{Inclusion Criteria:-}

1. Healthy subjects with completely edentulous mandibular ridge with moderate to severe resorption.

2. Patients without any systemic diseases or controlled systemic diseases.

3. Mandibular ridge with no severe undercuts so as to delimit the effect of undercut on retention.

\section{Exclusion Criteria:-}

1. Patients with major osseous surgery or any congenital or acquired osseous abnormality found in the mouth.

2. Patients with flabby ridges.

3. Patients with history of allergy to dental materials.

4. Patient with any pathology of oral mucosa.

\section{Making edentulous impressions:-}

Primary impressions were made in impression compound (Pyrex Polykem) using edentulous non-perforated stock trays and the casts were poured in Type II Dental plaster (Dentex-Prevest Dentpro). Two custom trays were fabricated on primary cast in visible light curing resin (Willmann \& Pein $\mathrm{GmbH}$ ) and these were reduced $2 \mathrm{~mm}$ short of the reflections for muscle trimming with tracing sticks of low fusing impression compound (DPI). The custom trays were then tried in patient's mouth and checked for comfort and extension.

\section{Border Molding:-}

Thereafter, border molding was done with first tray to proper extension by manual and functional movements using low fusing compound (green stick) and secondary impression was made with Zinc oxide Eugenol impression paste 
(DPI) (Fig.1). After verification, the impression was poured in Dental Stone (Type III - GypstonePrevest Dentpro) and master cast was fabricated and considered as Group A.

\section{Border Molding with sublingual extension:-}

Border molding with second tray was done with sublingual extension using low fusing compound (Fig.2). Low fusing compound was molded into a shelf extending downward and backward over the crescent region, patient was instructed to close and relax. The tongue should be in its normal rest position with the tip lightly touching the lingual surface of tray handle which will act as position of incisors. Secondary impression was made with Zinc oxide Eugenol impression paste. After verification, the impression was poured in Dental Stone (Type III) and master cast was fabricated and considered as group B.

\section{Duplication of the master cast:-}

Each mandibular cast was duplicated using elastomeric impression material (addition silicone - Willmann \& Pein $\mathrm{GmbH}$ ) for fabrication of two permanent denture bases on master casts of Group A and Group B (Fig.3).

\section{Fabrication of acrylic resin test bases:-}

The test bases were fabricated on the two duplicated casts using heat cure acrylic resin and processed according to the manufacturer's directions. The two test bases were designated as A and Bas per the cast on which they were fabricated. The test bases were finished and polished, and a wire loop of 19 gauge orthodontic wire (K.C. Smith \& co.) was placed on the center of the crest of ridge. Centre of crest of ridge was marked by joining two posterior reference points, its midline is marked using a surveyor (Fig. 4), a straight line was marked from that point to crest of ridge (Fig. 5). The loop was secured in position with the help of auto-polymerizing acrylic resin material (Fig. 6).

\section{Measurement of retention of denture bases:- Retention apparatus:-}

A specially designed apparatus consisting of a metallic stand and a digital force gauge was used to measure retention values.

Stand consisted of a base, a vertical arm and a movable T-shaped assembly having two pulleys. Nylon thread was passed over these pulleys which were attached to denture base at one end and force gauge at other end. A rectangular metal tube with adjustable L-shaped extension having chin rest was attached horizontally to vertical tube which can move up and down with the help of screws(Fig.7).

Digital force gauge (Lutron FG 5000 A) with 3 types of display units: gram, Newton and ounce were used. It had a measure capacity of $5000 \mathrm{~g} / 176.40 \mathrm{oz} . / 49.03$ Newton and overload capacity of $7000 \mathrm{~g}$, high resolution, high accuracy, and peak hold (Fig.8).

\section{Testing procedure:-}

The patient was seated upright in front of the testing device in a comfortable position. The chin of the patient was placed quite firmly in the chin rest. The test denture base attached to nylon thread was rinsed thoroughly with water prior to insertion in the patient's mouth to minimize the variable factors of retention which could be influenced by a change of salivary content and firmly seated on the foundation. The patient was instructed to keep the tongue in a relaxed position with its tip lightly touching against the lingual surfaces of the lower anterior teeth. Force gauge attached to other end of the nylon thread was slowly pulled down in vertical direction until the denture base was dislodged and peak value was recorded (in grams) for both the denture bases (denture bases A and B)(Fig.9).

\section{Results:-}

The basic data was collected from twenty patients on two denture bases obtained by conventional border molding and border molding with sublingual extension to compare retention. The dislodging forces for the two denture bases (A and B) of each subject were recorded (in grams) and the collected data was subjected to statistical analysis with IBM SPSS 24 windows software.

In order to test whether the increase in retention of test bases was statistically significant, an Unpaired T test (two tailed) was applied.

Decision criterion:-

p-value $<0.05$ indicates a significant difference between two groups. 
Group A - Conventional border molding with low fusing impression compound.

Group B - Border molding with sublingual extension with low fusing impression compound

Table I showed the mean values of retention of denture bases obtained by conventional border molding technique and border molding technique with sublingual extension respectively with range of means 11.87-77.80 grams and 19.40-96.27 grams respectively. Table II showed that the percentage increase in mean values of retention of denture bases obtained by border molding with sublingual extension as compared to conventional border molding was $40.07 \%$ with statistically significant difference of 0.038 .

Graph Iillustrates that there was increase in the mean value of retention (in grams) in group B as compared to group A among all the 20 patients. Graph II shows the comparison of mean values of retention of group A and group B which came out to be 39.9327 grams and 55.9350 grams respectively.

\section{Discussion:-}

The present in-vivo study was planned to determine the effect of sublingual extension on denture retention with or without sublingual extension. The objective was to measure the changes in retention of mandibular denture with extension in sublingual region and evaluate the impression method best suited for patients with mandibular ridge resorption. The comparisons were made based on the statistical analysis using the 0.05 level of significance.

It was observed that sublingual extension of denture base significantly improved the retention of denture base in resorbed ridges. The devices used by previous investigators include: spring balances ${ }^{16}$, lever arm with loading apparatus $^{17,18}$, Rhiele universal testing machine ${ }^{19}$, dial type push pull dynamometer ${ }^{20}$, strain gauge force transducer $^{21,22}$ and hydraulic and electronic system using an extra oral transducer. Digital force gauge (Lutron FG 5000 A) with 3 types of display units: gram, Newton and ounce was used in this study. It had a measure capacity of $5000 \mathrm{~g} / 176.40 \mathrm{oz} . / 49.03$ Newton and overload capacity of $7000 \mathrm{~g}$, high resolution, high accuracy, and peakhold.

In this study, increase in retention is due to extension of anterior lingual flange in sublingual space, the downward line of action of the major extrinsic lingual muscle, genioglossus, is consistent with these findings. Further, higher values are also because the direction of lingual force from genioglossus is downward rather than lateral. ${ }^{15}$ When anterior lingual flange does not extend to fornix of alveololingual sulcus, the retentive hydrostatic pressure gradient in fluid layer is substantially reduced between intaglio and soft tissue. ${ }^{1,2}$

Literature suggested that increase in width of sublingual region of denture could result in more retention, especially when tongue is in relaxed position. ${ }^{23}$ Tissues of sublingual region moves mainly in horizontal direction in normal swallowing and during function without raising sublingual gland.

Since the sublingual gland is flexible and highly compressible, and floor of mouth doesn't have firm muscular support, slight distension may not create instability of denture and may improve retention. ${ }^{2,14,15,23,24,25}$ Varying degrees of extensions over the sublingual gland of each side increases the area of contact of the denture base with the tongue and glands resulting in greater effective area of the base and greater retention regardless of minor degrees of tongue retraction. The limitation of this technique is that the tongue movements may be limited slightly due to the presence of sublingual crescents, but the patient will be adapted to this, if extensions are proper. Sublingual extensions if overextended will diminish the mandibular denture retention. ${ }^{7}$

In this study, the long term functional analysis was not conducted to determine if the subjects could tolerate the amount of dimensional changes created by extension in sublingual region. Further, time dependent assessment and long term patient satisfaction is needed in these patients.

Sublingual extension in complete dentures might be beneficial as a last resort in severely resorbed ridges because implants cannot be given as a means of retention for these patients. Overextended sublingual extension will diminish the mandibular denture retention. ${ }^{7,13}$. So, extensions should be properly recorded to avail the benefits of sub-lingual area. 


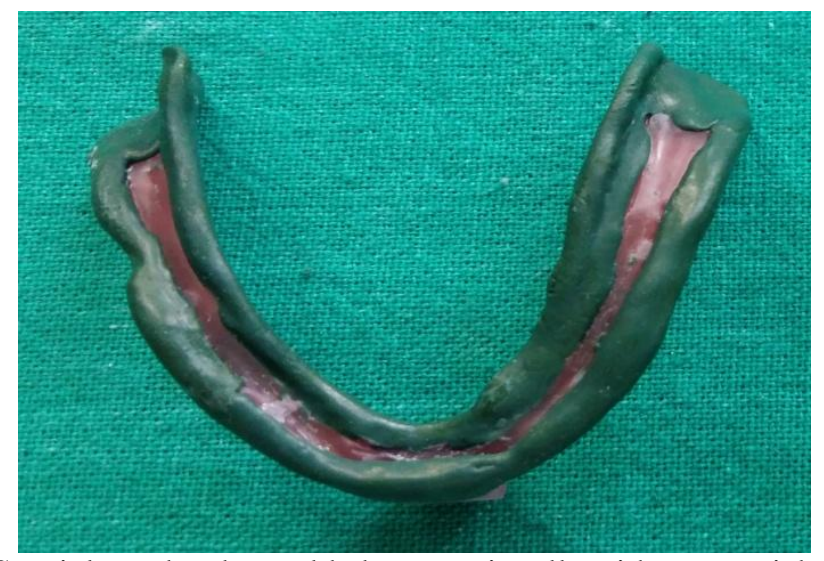

Fig. 1:-Special tray border molded conventionally with green stick

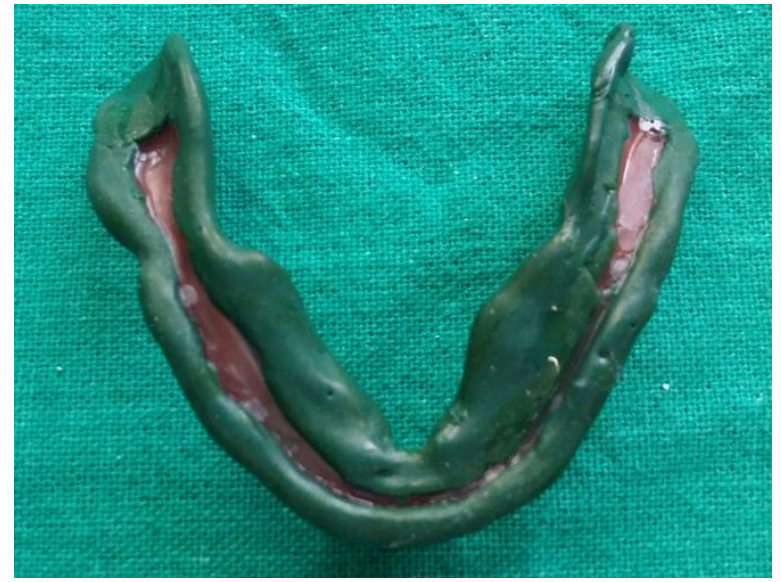

Fig.2:-Special tray border molded with sublingual extension using green stick

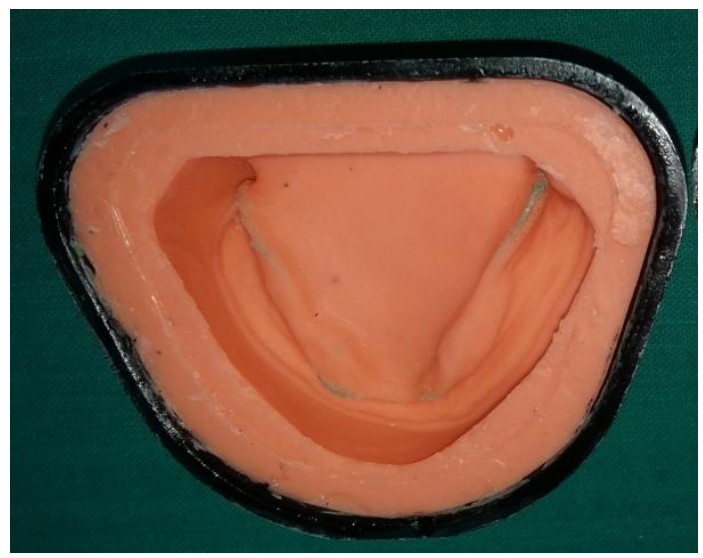

Fig.3:-Mold for duplication of master casts 


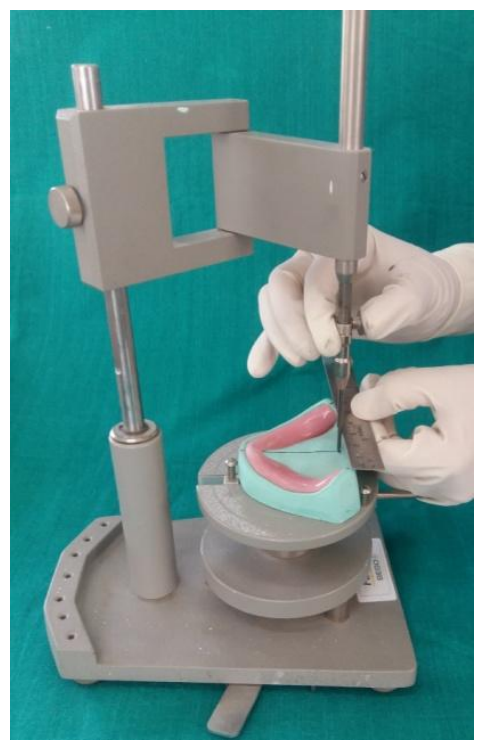

Fig. 4:-Reference points marked using surveyor

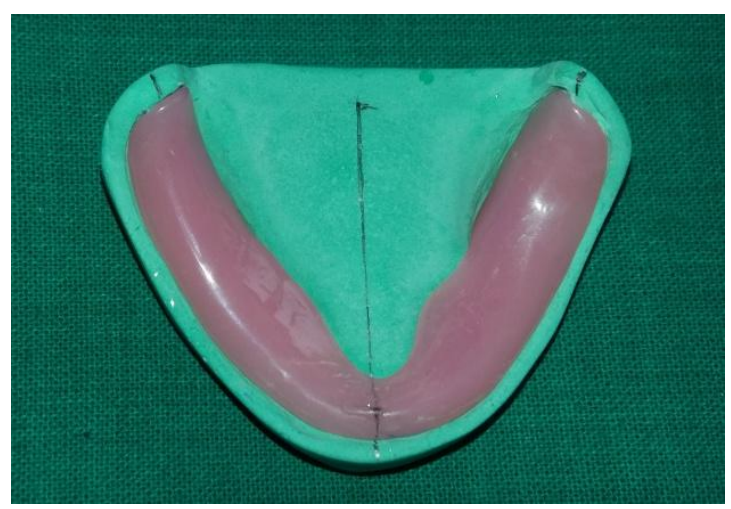

Fig. 5:-Marking of reference point on crest of ridge

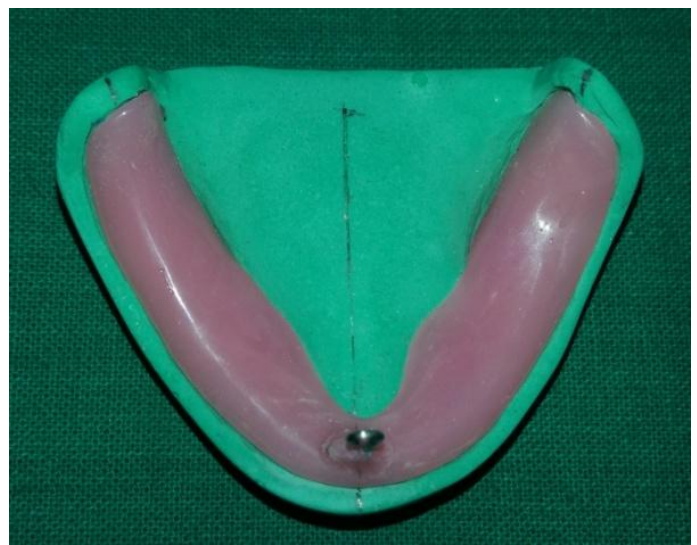

Fig. 6:-Fixation of wire loop 


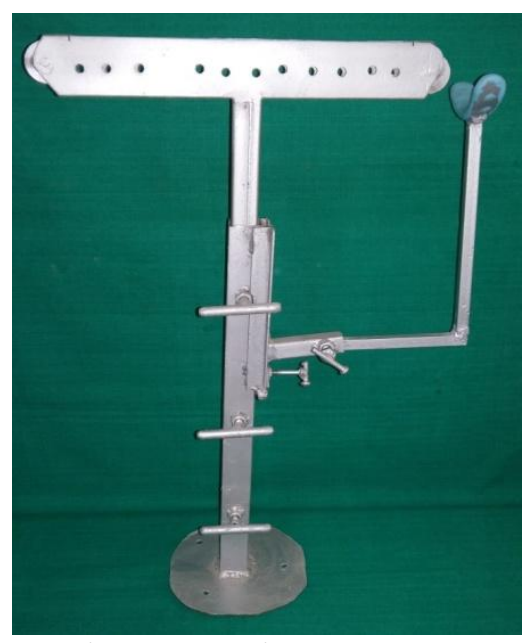

Fig.7:-Retention apparatus

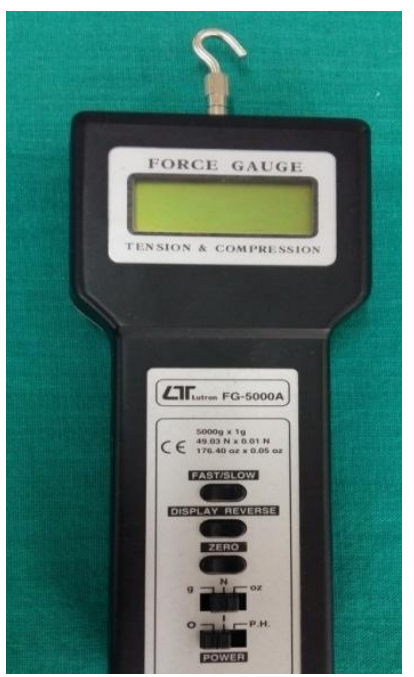

Fig.8:-Leutron FG-5000- Force gauge

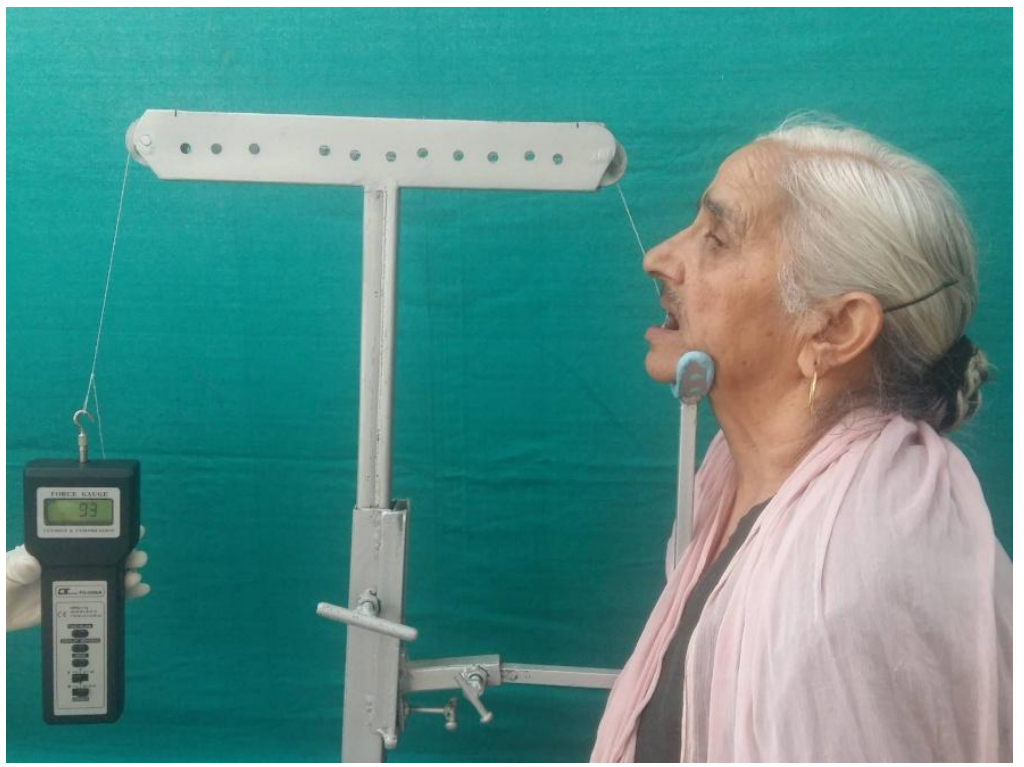

Fig. 9:-Testing procedure - retention of mandibular denture base being measured on the patient 
TABLE I:-Shows mean forces (in grams) for denture bases A and B

\begin{tabular}{|c|c|c|}
\hline Patient No. & Conventional Border Molding (A) & Border Molding with Sublingual Extension (B) \\
\hline 1. & 77.80 & 92.20 \\
\hline $\mathbf{2 .}$ & 40.73 & 60.40 \\
\hline $\mathbf{3 .}$ & 44.93 & 70.53 \\
\hline $\mathbf{4 .}$ & 11.87 & 19.40 \\
\hline $\mathbf{5 .}$ & 22.47 & 42.13 \\
\hline $\mathbf{6 .}$ & 60.87 & 75.27 \\
\hline $\mathbf{7 .}$ & 46.33 & 69.73 \\
\hline $\mathbf{8 .}$ & 22.20 & 40.17 \\
\hline $\mathbf{9 .}$ & 72 & 91.73 \\
\hline $\mathbf{1 0 .}$ & 23.48 & 39.33 \\
\hline $\mathbf{1 1 .}$ & 36.40 & 47.73 \\
\hline $\mathbf{1 2 .}$ & 46.33 & 54.67 \\
\hline $\mathbf{1 3 .}$ & 52.33 & 65.60 \\
\hline $\mathbf{1 4 .}$ & 73.93 & 96.27 \\
\hline $\mathbf{1 5 .}$ & 14.07 & 20.53 \\
\hline $\mathbf{1 6 .}$ & 64.27 & 94.93 \\
\hline $\mathbf{1 7 .}$ & 18.27 & 30 \\
\hline $\mathbf{1 8 .}$ & 35.33 & 52.27 \\
\hline $\mathbf{1 9}$ & 14 & 22.27 \\
\hline $\mathbf{2 0 .}$ & 21.04 & 33.53 \\
\hline
\end{tabular}

TABLE II:-Shows statistical analysis of retention of mandibular complete denture bases using "Unpaired T (twotailed) test"

\begin{tabular}{|l|l|l|l|l|l|}
\hline $\begin{array}{l}\text { Increase in } \\
\text { mean value of } \\
\text { retention }\end{array}$ & $\begin{array}{l}\text { \% increase in } \\
\text { mean value of } \\
\text { retention }\end{array}$ & $\mathbf{T}$ & df & Sig (2 tailed $)$ \\
\hline 16.002 & 40.07 & 2.147 & 38 & 0.038 & Sign \\
\hline
\end{tabular}

Graph-I:-Comparison of mean retention values between Group A and Group B

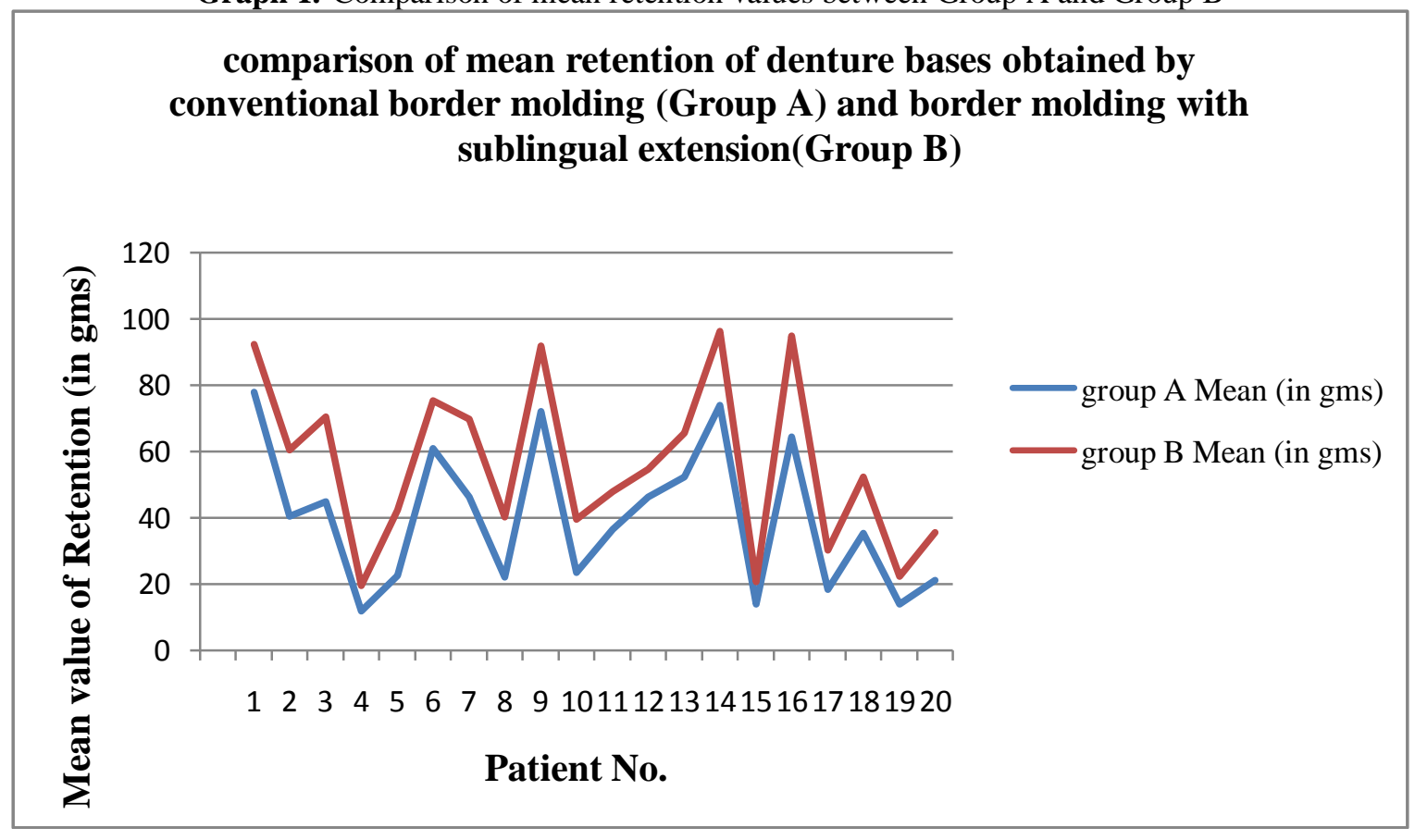


Graph-II:-Comparison of mean values of retention of group A and group B

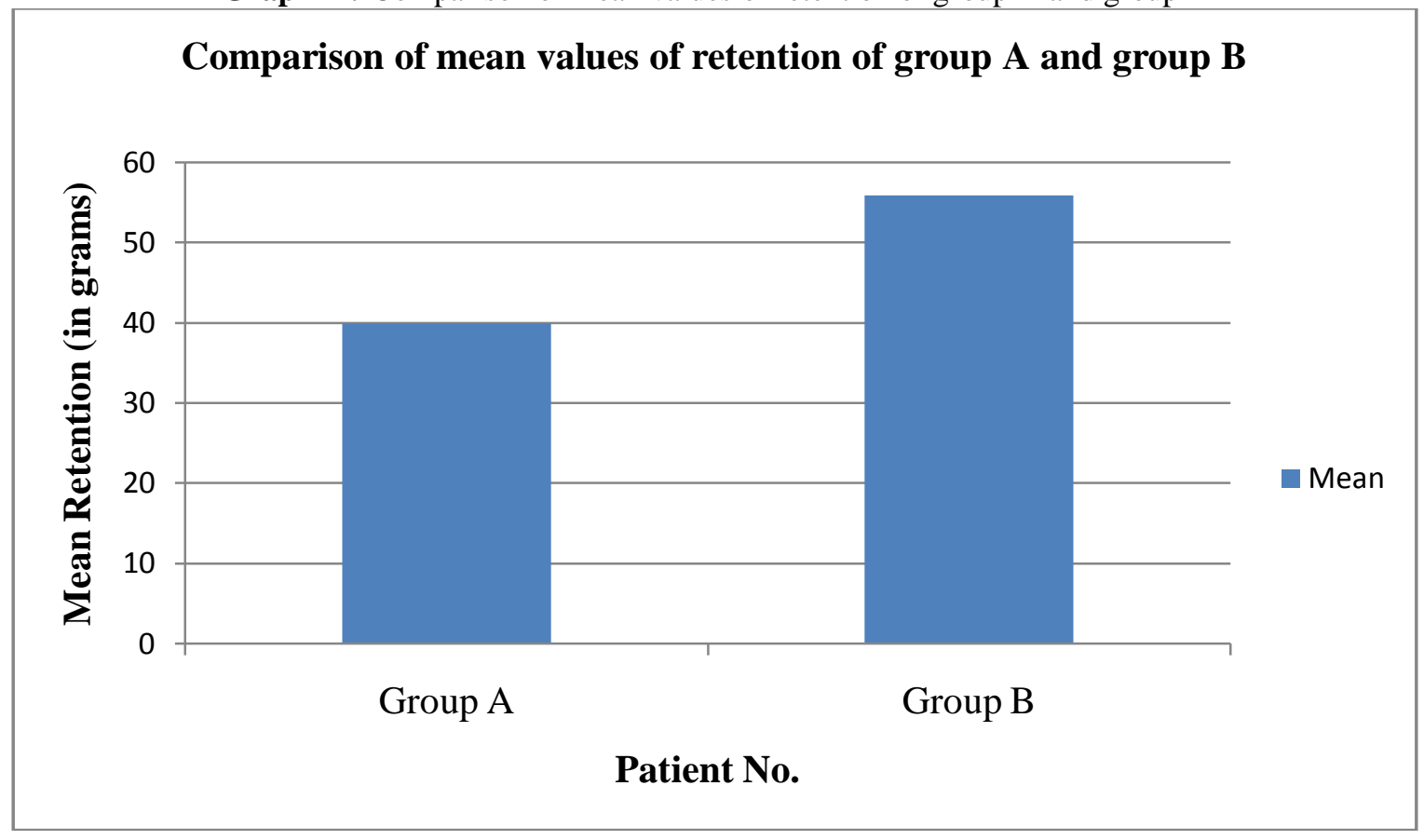

\section{Conclusion:-}

The results of this study indicated that sublingual extension significantly improved retention of denture bases. A modification in the border molding technique shows improvement in retention by increasing the area of contact and providing peripheral border seal.

Within the limitations of this study it was concluded that retention could be significantly increased after sublingual extension of the denture bases and the technique may be recommended as an adjunctive measure for improving the retention of complete dentures in patients with resorbed ridges.Although the results of this study show significant improvement in retention of denture bases after sublingual extension, further long term functional analysis is needed to determine if the subjects could tolerate the amount of dimensional changes created by extension in sublingual region.

\section{References:-}

1. Jacobson TE, Krol AJ. A contemporary review of the factors involved in complete denture retention, stability, and support. Part I: Retention. J Prosthet Dent 1983;49(1):5-15.

2. Chang JJ et al. Maximizing mandibular denture retention in the sublingual space. Int $\mathbf{J}$ Prosthodont 2011;24(5):460-4.

3. Kotkin H, Slabbert JCG, Dent HD, Dent M. Tongue position in relation to edentulous mandibular impressions. J Prosthet Dent 1987;57(4):458-62.

4. Denizoğlu S, Yanikoglu N, Yilmaz B, Kürklu D. Effects of tongue movements on lingual sulcus depth whileborder molding in mandibular complete dentures. Indian J Dent Research 2014;25(4):439-44.

5. Bohnenkamp DM, Garcia LT. Phonetics and tongue position to improve mandibular denture retention: A clinical report. J Prosthet Dent 2007;98(5):344-7.

6. Friedman S. Edentulous impression procedures for maximum retention and stability. J Prosthet Dent 1957;7(1):14-26.

7. Gafoor MAA, Kumar VVH, Sheejith M, Swapna C. Recording 'Sublingual crescents' in lower complete dentures: A technique so effective but still esoteric and arcane. J Contemp Dent Practice 2012;13(2):222-6.

8. Brill N, Tryde G, Cantor R. The dynamic nature of lower denture space. J Prosthet Dent 1965;15(3):401-18.

9. Willigen JD. Movement of mandibular sulci during normal tongue and mouth movements. J Prosthet Dent 1972;27(1):4-15. 
10. Jennings DE. Treatment of the mandibular compromised ridge: A literature review. J Prosthet Dent 1989;61(6):575-9.

11. Krammer RV, Dentista C. Principles and technique in sublingual flange extension of complete mandibular dentures. J Prosthet Dent 1982;47(5):479-82.

12. Bocage M, Lehrhaupt J. Lingual flange design in complete dentures. J Prosthet Dent 1977;37(5):499-506.

13. Azzam MKA, Yurkstas AA, Kronman J. The sublingual crescent extension and its relation to the stability and retention of mandibular complete dentures. J Prosthet Dent 1992;67(2):205-10.

14. Lewis ET. Repositioning of the sublingual fold for complete dentures. J Prosthet Dent 1958;8(1):22-5.

15. Miller WP, Monteith B, Heath MR. The effect of variation of the lingual shape of mandibular complete dentures on lingual resistanceto lifting forces Gerontology 1998;15(2):113-9.

16. Ostlund SG. Saliva and denture retention. J Prosthet Dent 1960;10(4):658-63.

17. Boucher LJ, Ellinger C, Lutes M, Kicky JC. The effect of microlayer of silica on the retention of mandibular complete dentures. J Prosthet Dent 1968;19(6):581-86.

18. Hamrick JE. Acomparison of the retention of various denture base materials. J Prosthet Dent 1962;12(4):66677.

19. Shwartz WH. Retention forces with different denture base materials. J Prosthet Dent 1966;16(3):458-63.

20. Neidermeier WHW, Kramer R. Salivary secretion and denture retention. J Prosthet Dent 1992;67(2):211-16.

21. Kawazoe Y, Hamada T. The role of saliva in retention of maxillary complete denture. J Prosthet Dent 1978;40(2):131-36-11.

22. Kikuchi M, Ghani F, Watanabe M. Method for enhancing retention in complete denture bases. J Prosthet Dent 1999;81(4):399-403.

23. Lawson WA. Influence of the sublingual fold on retention of complete lower dentures. J Prosthet Dent 1961;11(6):1038-44.

24. Mustafa AZ. Effect of the lingual ledge of neutral zone impression on the retention and stability of mandibular complete denture in elders with atrophied alveolar ridge. Tanta Dent J 2015;12:111-8.

25. Lewis ET. The genial tubercle space in full lower dentures. J Prosthet Dent 1954;4(5):606-10. 